Kelly Alves Magalhães ${ }^{1}$

Karla Cristina Giacomin ${ }^{2}$

Wagner Jorge dos Santos ${ }^{1}$

Josélia Oliveira Araújo Firmo ${ }^{1}$

${ }^{1}$ Núcleo de Estudos em Saúde Pública e Envelhecimento, Centro de Pesquisas René Rachou, Fiocruz. Av. Augusto de Lima 1715, Barro Preto. 30190-002 Belo Horizonte MG Brasil. kalvesmagalhaes@ gmail.com

${ }^{2}$ Secretaria Municipal de Saúde de Belo Horizonte.

\title{
A visita domiciliária do agente comunitário de saúde a famílias com idosos frágeis
}

\author{
Home visits by community health agents \\ to families with frail elderly individuals
}

\begin{abstract}
The scope of this study was to understand the significance that community health agents attribute to the home visit conducted with families with frail elderly individuals and if the technique has served as a tool for care for this group. Semi-structured interviews were conducted with community health agents in the city of Bambui in the State of Minas Gerais. They were all recorded, transcribed and analyzed. The Signs, Meanings and Actions model was used in the collection and analysis of data. In their ways of thinking and acting, seeing aging as being inexorably associated with disability, the agents "try to help" people who have a sociocultural context similar to theirs to get access to health services. As they do not receive guidelines for working with families with elderly individuals, they intuitively establish "equitable" criteria that ensure they visit more risk groups (the elderly, needy, sick and poor). The visits are in response to immediate demands from these groups, but the focus of attention is based on sickness and the provision of medication and procedures. The need for reorientation of the care model, implementation of the National Health Policy for the Elderly and specific actions of care to families with frail elderly individuals are not perceived.
\end{abstract}

Key words Community health agents, Care, Aging, Family health strategy, Home visit
Resumo Objetivou-se compreender os sentidos que os agentes comunitários atribuem à visita domiciliária realizada junto a famílias com idosos frágeis, e também se esta tecnologia de trabalho tem servido como uma ferramenta de Cuidado a este grupo. Foram realizadas entrevistas a agentes comunitários do município de Bambui/MG, guiadas por roteiro semiestruturado. Todas foram gravadas, transcritas e analisadas. O modelo Signos, Significados e Ações guiou a coleta e a análise dos dados. Em suas maneiras de pensar e agir, percebendo a velhice, inexoravelmente associada à incapacidade, as agentes "tentam ajudar" pessoas que vivenciam um contexto sociocultural similar ao seu a ter acesso aos serviços de saúde. Como não recebem orientações para atuar junto às famílias com idosos, intuitivamente estabelecem critérios "equitativos", ancorados em uma dimensão solidária, visitando mais os grupos de risco (o idoso, o carente, o doente, o pobre). A visita ocorre em resposta a demandas imediatas destes grupos, mas o foco da atenção permanece pautado na doença e na oferta de insumos e procedimentos. A desejada reorientação do modelo assistencial, a implementação da Política Nacional de Saúde da Pessoa Idosa e as ações específicas de cuidado às famílias com idosos frágeis não foram notadas.

Palavras-chave Agente Comunitário de Saúde, Cuidado, Envelhecimento, Estratégia de Saúde da Família, Visita domiciliária 


\section{Introdução}

Frente ao acelerado e intenso envelhecimento populacional brasileiro ${ }^{1,2} \mathrm{e}$ à importância do sistema de saúde como determinante de saúde da população, a Estratégia Saúde da Família (ESF) assume papel fundamental no processo de cuidado à população idosa ${ }^{3}$. O modelo de atenção proposto pela ESF busca reorientar as práticas de saúde e o processo de trabalho dos diferentes profissionais ${ }^{4}$, bem como responder às demandas de cuidado da população adscrita. $\mathrm{Na}$ velhice, tais demandas são diferenciadas ${ }^{2,3}$ e exigem uma abordagem integral, interdisciplinar, multidimensional, que considere a interação entre os fatores físicos, psicológicos, ambientais e socioculturais que influenciam a saúde $e^{4}$ inclusive a comunidade, o domicílio e a família dos idosos.

Ante o processo saúde-doença-envelhecimento que envolve indivíduos e coletividades, a funcionalidade se mostra como uma dimensão fundamental, pois seu comprometimento aumenta o risco de problemas de saúde ${ }^{4}$. A Política Nacional de Saúde da Pessoa Idosa (PNSPI) ${ }^{3}$ utiliza como parâmetros, para definir uma pessoa idosa frágil ou em situação de fragilidade: ser maior de 75 anos, estar acamado, vivenciar situações de violência doméstica, e ou apresentar doenças sabidamente causadoras de incapacidade funcional (acidente vascular encefálico, síndromes demenciais e outras doenças neurodegenerativas, etilismo, neoplasia terminal, amputações de membros).

A incapacidade funcional refere-se às limitações e dificuldades na realização de atividades cotidianas, em qualquer domínio da vida e/ou a restrição na participação social, resultante da interação dinâmica entre as condições de saúde e os fatores contextuais do indivíduo ${ }^{5}$. Trata-se de uma condição influenciada por múltiplos fatores ${ }^{6}$, que demanda cuidados em saúde e deve ser referenciada a um universo sociocultural específico ${ }^{7}$.

Quando indivíduos idosos não conseguem comparecer ao serviço de saúde em razão de alguma incapacidade, a visita domiciliária - atividade externa à Unidade Básica de Saúde (UBS) mais realizada pela equipe de saúde ${ }^{8}$ - assume importância crucial, pois permite conhecer in loco a realidade e as necessidades das famílias e de seus membros. Trata-se de uma ferramenta de cuidado e promoção da saúde ${ }^{10}$, de busca ativa e identificação da demanda reprimida, de diagnóstico local e de planejamento de ações a partir da realidade, de mediação entre as famílias e as equipes de saúde. Esta mediação entre o serviço de saúde e a comunidade é função primordial do Agente Comunitário de Saúde (ACS $)^{10,11}$, profissional com múltiplas atribuições, dentre as quais a visita $^{12}$.

Assim, o presente trabalho objetiva compreender os sentidos que os agentes atribuem à visita domiciliária realizada junto a famílias com idosos frágeis e se esta tecnologia de trabalho tem servido como ferramenta de Cuidado a este grupo populacional.

\section{Quadro teórico}

Segundo Ayres ${ }^{13}$, o Cuidado designa uma atenção à intimamente relacionada ao sentido existencial da experiência do adoecimento físico ou mental, e, consequentemente, também às práticas de promoção, proteção ou recuperação da saúde. Este autor utiliza o termo em maiúsculo para diferenciar daquele cuidado referente a atividades e procedimentos no sentido comum ${ }^{13}$, com significado diverso do que se propõe a discutir. Assume-se o Cuidado como um fato político, uma categoria sociocultural cuja concretização se faz no cotidiano da vida das pessoas, nos diferentes espaços e contextos ${ }^{14}$, onde deveria acontecer o encontro entre os sujeitos envolvidos, o que perpassa o acolhimento (por meio da escuta qualificada do outro) e a humanização das práticas de saúde, cujo desafio consiste em aproximar as tecnociências com os valores da felicidade humana. Esta última diz respeito essencialmente a uma experiência de caráter singular e pessoal, conforme atesta a proposta política de humanização da atenção à saúde, ancorada em valores que de forma democrática validem e propiciem a felicidade, envolvendo também as instituições do Estado ${ }^{13}$. Para tanto, reclama a (re)significação não apenas da saúde, mas do projeto de vida do sujeito, do serviço, da práxis profissional, o que permitirá estabelecer um vínculo terapêutico efetivo.

Este trabalho volta-se à compreensão dos significados que as pessoas (ACS) atribuem às suas experiências e como compreendem o mundo em que vivem ${ }^{15}$. Nesta abordagem, analisa-se o universo de significados, motivações, aspirações, crenças, valores e atitudes, o que corresponde a um nível de realidade que não pode ser quantificado, pois os processos e fenômenos investigados não são redutíveis a variáveis ${ }^{16}$. Tal significado é partilhado culturalmente, organizando o grupo social em torno de simbolismos e representações ${ }^{17}$ enquanto categorias de pensamento, de ação e de sentimento, que expressam a realidade, explicando-a, justificando-a ou questionando-a ${ }^{16,18}$. 
A corrente interpretativa da antropologia considera uma nova concepção da relação entre indivíduos e cultura ${ }^{18}$ - o contexto no qual os diferentes eventos se tornam inteligíveis -, compreendendo cultura como um universo de símbolos e significados que permite aos sujeitos de um grupo interpretar suas experiências e guiar suas ações ${ }^{19}$. Enquanto na perspectiva da Antropologia Médica, a saúde e o que se relaciona com ela (o envelhecimento e o Cuidado), bem como as percepções, interpretações e ações relativas a tais fenômenos são culturalmente construídos e culturalmente interpretados ${ }^{14,18}$. Para fazê-lo as pessoas se apoiam em conceitos, símbolos e estruturas interiorizadas, conforme os grupos sociais a que pertencem ${ }^{20}$.

\section{Métodos}

Esta pesquisa qualitativa, de cunho antropológico, foi conduzida em Bambuí, Minas Gerais, município de atividade agropecuária, a 212,2 km da capital Belo Horizonte, com cerca de 23 mil habitantes, $85 \%$ deles urbanos ${ }^{21}$. A ESF estava implantada nas seis UBS, sendo uma equipe por UBS e seis a sete ACS por equipe. A seleção dos participantes considerou como critérios o território (todas as UBS) e a experiência profissional como ACS. Por se tratar de uma abordagem qualitativa, o número de entrevistas foi regulado pelo critério de saturação ${ }^{22}$.

Entre fevereiro e abril de 2011, após consentimento livre e esclarecido dos informantes, foram realizadas, nas UBS, entrevistas abertas e individuais, guiadas por um roteiro semiestruturado, que incluíram questões referentes ao cotidiano da ESF e do processo de trabalho do ACS em Bambuí, especialmente a visita domiciliária realizada junto às famílias com idosos. Todas as entrevistas foram gravadas e transcritas, permitindo a leitura atenta para identificar categorias analíticas, a interação entre diferentes categorias e sua articulação com o contexto sociocultural vigente $^{1}$.

Fundamentado na corrente interpretativa da antropologia, o modelo Signos, Significados e Ações ${ }^{23}$, guiou a coleta e análise dos dados. Ele possibilita o acesso a lógicas conceituais privilegiadas por uma população específica - no caso os ACS - e a sistematização de elementos contextuais que participam da construção de maneiras típicas de pensar e agir para compreender e explicar uma determinada condição ou fenômeno, a partir da identificação de comportamentos concretamen- te adotados por essa população ${ }^{1,18,24}$. A análise começa com o nível pragmático das narrativas identificando signos das ações e reações e, em seguida, evolui para o nível semântico ao produzir a compreensão dos significados, promovendo um diálogo entre a particularidade de condutas relacionadas à saúde e a generalidade do modelo biomédico, iluminando as lógicas culturais que explicam as convergências e divergências ${ }^{1}$.

Esta pesquisa é parte do projeto "Abordagem Antropológica da Dinâmica da Funcionalidade em Idosos" aprovado pelo Comitê de Ética em Pesquisa com Seres Humanos do Centro de Pesquisa René Rachou.

\section{Resultados e discussão}

Foram entrevistadas 24 ACS, todas mulheres, com idade entre 21 e 48 anos, a maioria casadas. Vinte concluíram ensino médio, sendo cinco técnicas em enfermagem e quatro graduandas em cursos diversos. Todas eram contratadas, a maioria estava no cargo há menos de quatro anos, variando de três meses a nove anos. Na zona urbana de Bambuí, o número de famílias acompanhadas por ACS variou de 135 a 191, chegando a 270 na zona rural. Para ser fiel às narrativas, manteve-se o termo utilizado pelas agentes - "PSF" (Programa de Saúde da Família) para se referir à ESF.

Inicialmente, é importante compreender quem é, na visão das ACS, este sujeito idoso que demanda e recebe visitas e como esta se configura no cotidiano das agentes. Ademais, para acompanhar todas as famílias e indivíduos de sua área de abrangência, as ACS estabelecem critérios que merecem ser avaliados e discutidos quanto aos mecanismos e significados que atribuem para definir o quê, quem e como priorizar essa visita, bem como aos seus desdobramentos para o Cuidado à saúde dos usuários, especialmente os idosos. Da análise das entrevistas, emergiram três categorias no campo da fala das ACS: quem é a pessoa idosa que demanda a visita domiciliária; a configuração prática da visita domiciliária do ACS; a visita domiciliária a famílias com idosos frágeis: critérios, significado e o Cuidado.

\section{Quem é a pessoa idosa que demanda a visita domiciliária}

Uma agente, referindo-se ao seu próprio envelhecimento associa o precisar do SUS (Sistema Único de Saúde) como um sinal de que ser idoso é adoecer e precisar de cuidados médicos; 
enquanto outra agente explica: a pessoa idosa é aquela que já tá incapacitada de fazer muitas coisas, que necessita de cuidados. Porque os jovens, eles não necessitam de cuidados (A2). Ademais, as agentes utilizam o termo "acamados" para se referir à pessoa idosa, pelas suas dificuldades em fazer as coisas sozinho. Nesse sentido, elas reconhecem a incapacidade funcional como balizadora da atenção à saúde que oferecem à pessoa idosa, o que concorda com a PNSPI ${ }^{3}$. Porém, esta necessidade de cuidados aparece confundida com a infantilização da velhice: O idoso depende de tudo da pessoa que tá cuidando dele. [...] vamos supor que tem um idoso acamado, às vezes não conversa direito, você tem que saber a hora dele alimentar, a hora que ele quer uma água, tem que trocar às vezes que usa fralda [...] É igualzinho você cuidar de uma criança recém-nascida (A19).

Embora o aspecto cronológico tenha aparecido nas falas, ainda que com variações em sua delimitação (60 a 80 anos), as perdas, as limitações (físicas, cognitivas e afetivas) e as dificuldades cotidianas, a dependência e a necessidade de cuidados de terceiros foram identificadas pelas ACS como definidores da velhice. Nos relatos, foram destacados o corpo e os sinais físicos do envelhecimento, bem como o adoecimento, a medicalização, a dor e a consequente demanda por serviços e insumos biomédicos, os quais serviam para definir quem era o sujeito idoso e interferiam nos modos de cuidar desta população.

Ainda que a prevalência da incapacidade aumente com a idade, a idade sozinha não prediz a incapacidade ${ }^{4}$, mas no contexto sociocultural local observa-se uma associação “inexorável” velhice-doença-incapacidade ${ }^{25}$, conforme outros trabalhos de cunho antropológico realizados junto a jovens $^{26}$ e a idosos ${ }^{27-29}$ na mesma cidade.

Nas visitas a famílias com idosos frágeis, as agentes buscavam o verdadeiro sentido e função dessa prática no âmbito da ESF, desempenhando seu papel de mediador e elo da integração entre o serviço de saúde e a comunidade, aproximando o cuidado do território, do ambiente familiar. Porém, resta saber se essa visita serve como ferramenta de cuidado para os idosos frágeis, no que consiste tal cuidado e se as entrevistadas se reconhecem como agentes do Cuidado.

\section{A configuração prática \\ da visita domiciliária do ACS}

Tecnicamente, a visita domiciliária compreende quatro etapas: planejamento, execução, registro de dados e avaliação do processo $^{30}$, cuja programação deveria ser feita conjuntamente com a equipe de saúde considerando os critérios de risco e vulnerabilidade, de modo que famílias com maior necessidade fossem visitadas mais vezes $^{12}$ pelos agentes.

Porém, a realidade retratada pelo grupo ainda se distancia do que está teorizado, expondo o dilema entre a quantidade e a qualidade da visita efetuada: (referindo-se à coordenadora) Não queria saber a qualidade, queria número de visitas. Agora a enfermeira caiu em si, falou: 'gente, o importante não é o número de visitas'. Porque você pode ir ali, em cinco minutos pegar uma assinatura e nem conversar com a pessoa (A18). Assim, se o objetivo principal da visita das ACS se resumir à coleta de assinaturas, a meta gerencial será atingida, mas o Cuidado não.

Outra ACS relata como organiza a visita: Dou a volta no quarteirão, que às vezes (alguém) tá precisando de alguma coisa, tá me vendo ali. Sempre eu falo: 'oh, tá precisando de alguma coisa, tal horário, que de manhã eu vou na rua de cá e à tarde eu passo na de lá; tal hora eu tô passando por aqui. Aí eles sempre ficam do lado de fora esperando (A6). Portanto, no seu campo de fala, a organização da visita domiciliária não é pautada pelo planejamento prévio e/ou pela finalidade da intervenção, mas pelo acaso ou demanda explícita do usuário, o que pode comprometer o sucesso dessa prática profissional ${ }^{10}$. Nenhuma delas relatou a realização de visitas para atender a demandas específicas da atuação da equipe, mas para dar respostas ao enfermeiro-chefe, à gestão e ao sistema, o que contribui para que a equipe de saúde desconheça o território adscrito e continue realizando visitas focadas apenas nas doenças das pessoas. Ademais, ainda prevalece, no grupo, a ideia de saúde como bem de consumo, servindo como parâmetros de avaliação da atenção das equipes: o fornecimento de medicamentos, a disponibilização de serviços ou a ampliação de cobertura $^{31}$.

Ao retornar para o serviço e repassar dados e registros ao chefe da equipe (o enfermeiro), as agentes se limitam a comprovar a realização da visita, sem relatar quaisquer orientações sobre a sua sistematização no prontuário da família para o acompanhamento e assistência contínua pela equipe e para a avaliação da própria efetividade dessa atividade ${ }^{30}$.

Nessa perspectiva, a interação usuário-ACSgestão, limitada ao fornecimento de insumos e à comprovação da visita domiciliária, incorre no risco de continuar "proporcionando mais do mesmo", permanecendo centrada no preen- 
chimento de fichas e relatórios e no registro de informações técnicas ligadas apenas ao aspecto biológico de doenças. Dessa forma, além de comprometer a vigilância à saúde e o reordenamento do modelo assistencial proposto pela ESF, a visita reproduz e reforça o modelo biomédico hegemônico. Para Franco et al. ${ }^{32}$, se a lógica da programação em saúde permanece burocrática, a produção do Cuidado se mostra pouco comprometida com uma prática clínica cuidadora.

Além disso, as pessoas visitadas demandam a atuação das ACS em uma gama de questões que, isoladamente, a medicina tecnológica e/ou o serviço não conseguem resolver ou amenizar, tais como: pobreza, violência, alcoolismo, as quais requerem planejamento e ações intersetoriais ${ }^{33}$. Tais situações dificultam as visitas, geram medo e insatisfação das agentes com o trabalho, visto que ficam cotidianamente expostas às situações de risco sem, contudo, ter acesso a ferramentas de enfrentamento ${ }^{34}$. Logo, cabe a pergunta: nesta visita ocorre um verdadeiro encontro entre as ACS e os usuários, tão necessário ao processo de Cuidado ${ }^{13}$ ?

\section{A visita a famílias com idosos frágeis: critérios, significado e o Cuidado}

No campo de fala das agentes, o acesso e o acompanhamento pela ESF variam conforme certos critérios, porque como explica esta ACS: Nem todo mundo precisa. [...] São mais jovens, que não têm doença, que não toma nenhum tipo de medicamento, que se considera sadios. [...]. Que tem plano. Acha que não vai precisar do PSF. Então não precisa receber visitas do agente (A17). Em sua rotina de trabalho, as agentes visitam mais quem, intuitivamente, julgam precisar mais: [tem idoso] que precisa de insulina, de remédio, então a gente tem que voltar mais. (A10); Tem muitas senhoras que fica sozinha, às vezes passa na rua, elas me chamam mais pra conversar, nem sobre às vezes saúde. Mais é atenção, ficam muito só (A13). Isso confirma que usuários idosos, especialmente aqueles que não contavam com uma rede de suporte familiar fortalecida, valorizaram a visita do ACS, o qual desempenhava importante papel no apoio social a esta população ${ }^{35}$.

Assim, valendo-se da concepção aristotélica de 'equidade' - as pessoas não são iguais e, portanto, não deverão receber coisas iguais ${ }^{36}$-, as agentes definem a frequência e periodicidade das visitas, entendendo que o PSF deveria investir mais onde a carência é maior, o que possibilitaria reduzir desigualdades. Elas optam por se voltar prioritariamente para grupos menos favorecidos e com problemas de saúde fortemente determinados por piores condições socioeconômicas e dificuldades de acesso aos serviços de saúde. Esse cuidado ofertado pelas ACS por meio das visitas domiciliárias representa uma forma de facilitar para o usuário, intercedendo em favor do indivíduo idoso junto a outro profissional para favorecer o acesso a consultas, procedimentos e insumos disponíveis no serviço, especialmente para quem se encontra acamado.

Porém, tais visitas são pensadas para o indivíduo enquanto grupo de risco (o idoso, o carente, $o$ doente, o pobre) e a atenção permanece focada na intervenção médica individual e pautada na doença-adoecimento (o diabético, o hipertenso, o que utiliza mais medicamentos e/ou pede receita médica, os mais dependentes). Assim, embora as ACS não disponham de orientações de como agir junto às famílias com idosos frágeis, os critérios "equitativos" que elas estabelecem denotam, em última análise, que a solidariedade e a dimensão relacional que os sustenta por certo escapa às estratégias usuais de controle gerencial ${ }^{14}$.

Apesar de defenderem em seus relatos que a atenção à pessoa idosa deveria ser prioritária e tal prioridade estar prevista em várias normas de abrangência nacional ${ }^{2,3}$, na sua prática, as agentes constatam a omissão do poder público, como nesta fala: Não tem muito o que eu fazer, porque pra mim fazer alguma coisa não depende de mim, depende de outras pessoas, de outros órgãos. Igual Estatuto do Idoso, acho que não faz nada pra ajudar essas pessoas. [...]. Acho que o governo deveria investir mais para o idoso ou talvez investe e aqui não tenha um órgão que faça isso (A8).

De fato, apesar dos avanços em relação às políticas brasileiras de proteção social e de saúde, estas ainda se apresentam muito restritas e largamente insuficientes em relação à oferta de serviços e programas de saúde pública e à amplitude e abrangência da sua intervenção junto à população idosa ${ }^{3,7}$, especialmente a parcela dependente de cuidados continuados ${ }^{37}$.

Em se tratando de famílias com idosos frágeis, as visitas domiciliárias possibilitariam a identificação e busca ativa dessas pessoas, encaminhando-as para uma avaliação global e para a construção de um plano terapêutico de cada caso/família pela equipe de saúde, de modo a intervir precocemente na perda da autonomia e evitar a dependência funcional ${ }^{3,4}$. Porém, diferentemente do recomendado ${ }^{30}$, as ACS não recebem no serviço orientações acerca do Cuidado de pessoas idosas com incapacidade (prevenção de 
quedas, riscos ambientais, processos demenciais, polifarmácia, entre outros) nem sobre como agir junto às famílias. Nenhuma das entrevistadas sequer menciona a Caderneta de saúde da pessoa idosa, considerada uma estratégia do Ministério da Saúde para o acompanhamento da saúde desta população ${ }^{38}$.

Durante e a partir das visitas, as ACS se esforçam para convencer o usuário a se cuidar. Isso inclui repassar informações; aconselhar sobre práticas e hábitos saudáveis; acompanhar e estimular o controle de pressão arterial e glicemia, imunização, realizando busca ativa quando necessário, além da entrega de medicamentos e receitas, agendamento de consultas e exames, escuta e diálogo, e o reforço ao vínculo entre a equipe e a comunidade, favorecendo a atuação dos demais profissionais da equipe de saúde ${ }^{11}$. Quanto à vigilância à saúde, vincula-se à noção de controle de consultas, insumos e medicamentos.

As ações realizadas pelas ACS bambuienses não estão sistematizadas em procedimentos, orientações, observações, entrevistas e encaminhamentos referentes à família que tem idosos frágeis, sendo guiadas por demandas e necessidades imediatas daqueles que as procuram. Isso fala a favor do seu compromisso pela resolução dos problemas a partir do que conseguem fazer, mas não do reordenamento do modelo assistencial, pois as metas de gestão continuam referenciadas pelas doenças, centradas no indivíduo como unidade de cuidado e não na família.

Essa situação faz com que o termo 'família' perca sua especificidade e torne qualquer intervenção da equipe como familiar ${ }^{39}$. Importante reconhecer que a atuação da ACS não se dá de forma isolada, mas revela um serviço que também não identifica como foco da atenção: a família com pessoas idosas - frágeis ou não; a família palco de violência doméstica contra a pessoa idosa; a família que demanda insumos do serviço para alguém idoso (procedimentos, medicamentos, curativos, dietas, reabilitação domiciliária); a família unipessoal (pelo risco do isolamento) ou multigeracional (pelo risco de negligência para com as pessoas idosas).

Além disso, a atenção à saúde focada no indivíduo não se mostra eficaz na prevenção, educação e intervenção em questões sociais, ficando restrita ao gerenciamento das complicações referentes a afecções crônicas e indevidamente acompanhadas ${ }^{4}$. Assim, o risco familiar relacionado à presença de características, seja na família ou em algum de seus membros, que os coloquem sob maior ou menor probabilidade de exposição a fatores prejudiciais à saúde passíveis de causar agravos de ordem física, psicológica ou social ${ }^{40}$, poderia embasar um apoio matricial a estas famílias com idosos frágeis para auxiliar a equipe no planejamento e tomada de decisões. Contudo, na prática, isso ainda não acontece.

Apesar disso, as agentes visitam, descobrem, acolhem e escutam a pessoa idosa que demanda cuidados a uma família, que também tem limitações, enquanto todos os sujeitos do cuidado envolvidos sofrem com o despreparo e a insuficiência das políticas públicas para este cuidado continuado ${ }^{2,3,37}$. Ao adentrar os domicílios, entre algumas surpresas e muitas incertezas, as agentes reconhecem e experimentam emoções e situações da vida real, marcadas por relações complexas, inclusive entre o PSF e a família visitada, que expõem uma população historicamente desassistida, da qual a própria agente participa.

Importante reconhecer que o processo de trabalho em saúde é sempre relacional, aberto à presença do trabalho vivo em ato, por isso mesmo podendo sempre ser "atravessado" por lógicas distintas e pela criatividade permanente do trabalhador em saúde, como lembra Merhy ${ }^{41}$. Assim, apesar de reproduzirem uma atenção à saúde "contaminada" pelo modelo biomédico, as agentes fazem da visita uma ferramenta de cuidado que ultrapassa a dimensão biológica da saúde e adentra a intimidade da vida privada. Uma ACS explica: Quando elas se torna amiga, elas contam muito o que acontece dentro de casa pra gente e não tem coragem de contar pra um filho. A gente passa a ser uma amiga. Porque a gente, que trabalha como agente, tem que ter sigilo, a ética profissional. O que ouve lá não pode passar pra frente (A1). Assuntos particulares se tornam visíveis e alvo de avaliação dos profissionais de saúde, o que coloca o vínculo e a confiança em linha tênue ${ }^{33}$, trazendo à tona aspectos éticos com os quais as ACS se deparam.

Dessa forma, o trabalho das ACS no cuidado à saúde da pessoa idosa se organiza na operação de inúmeras interfaces que compõem o campo da saúde e seu fazer se interpõe no curso entre a dimensão tecnológica e a dimensão solidária e social, as quais têm potenciais conflitos na dinâmica cotidiana, pois visam conciliar ações técnico-assistenciais com aspectos sociais ${ }^{42}$. Compreende-se que, para as agentes, cuidar significa mais do que tratar o sujeito nas unidades de saúde, incluindo prover assistência na vida comunitária, exercendo o cuidado no território onde se insere a população adscrita ${ }^{43}$. Todavia, a solidariedade, a compaixão e o fato de as tarefas das agentes se 
sobreporem às de outras categorias, podem levá -las a confundir seu papel e ultrapassar os limites de sua competência, como neste relato: Tem uma senhora na minha área, que ela até morreu tem pouco tempo, eu dava até banho nela, na casa dela. [...] porque tinha muito tempo que eu tava tratando da ferida dela (A6).

Além disso, a ausência de planejamento sistemático das visitas junto à equipe e sua reprodução burocrática - preenchimento de fichas, atualizações rotineiras e comprovação por meio de assinatura do usuário - reduzem-na a uma atividade social e dificultam a construção de novas relações entre os usuários e a equipe e, em ultima análise, a criação de vínculo ${ }^{33}$, bem como a transformação de um modelo de atenção procedimento-centrado para família-usuário-centrado. Essas contradições e estranhamentos na rede de atenção à saúde que decorrem de relações hierárquicas nas equipes e de ações centradas no enfoque curativo, assistencialista, com orientações voltadas para determinadas doenças e guiadas por programas preestabelecidos, podem mascarar as reais necessidades de saúde da população ${ }^{44}$ e prejudicar o acompanhamento das famílias.

Nesta estreita relação entre o universo das representações (maneiras de pensar) e dos comportamentos (maneiras de agir) ${ }^{24}$, a ACS vai ao campo, preocupada em "ajudar" pessoas idosas, as quais reconhece, intuitivamente, como vulneráveis. Ao tentar responder aos anseios da população adscrita -, embora em um invólucro de visita promotora do acesso a procedimentos, insumos, consultas e medicamentos -, identificada com a mesma rede sociocultural e semântica de cuidado da população assistida, a ação das agentes ainda reforça o significado de saúde como bem de consumo. Muito embora essa motivação solidária possa servir para humanizar o cuidado, emerge das falas a ausência da compreensão abrangente de saúde e de Cuidado proposta pela ESF.

Assim, o significado da visita domiciliária a pessoas idosas no âmbito da ESF para as ACS transita entre o exercício de sua solidariedade, especialmente por meio da escuta, e o cuidado no sentido predominantemente biomédico. O acompanhamento domiciliar de idosos com algum tipo de incapacidade funcional revela as múltiplas fragilidades de todos os sujeitos de cuidado envolvidos. Primeiramente, as fragilidades da pessoa idosa que precisa ser cuidada e as da comunidade em que vive, frente ao sofrimento vivenciado pelas famílias que cuidam de pessoas que envelhecem sem contar com uma rede de suporte social adequada e com o apoio sistemá- tico do SUS. Também aparecem as fragilidades do serviço público de saúde, pois faltam políticas e ações voltadas para idosos e suas famílias, deixando as agentes diante das próprias limitações, enquanto profissionais de saúde no exercício desse cuidado.

Se se pretende o reordenamento do cuidado como práxis mediadora e inovadora da ação em saúde pelas agentes, há que se insistir em ações sucessivas e abrangentes de inclusão, dignificação, visibilidade, reconhecimento e corresponsabilização de todos os atores envolvidos no cuidado a famílias com idosos frágeis - usuário, agente, equipe, gestor ${ }^{31}$. Quando realizada de forma dialógica e voltada para a realidade, às necessidades locais e ao acompanhamento longitudinal das famílias, a visita possibilita este reordenamento, ao promover o vínculo e a responsabilização ${ }^{8}$, reconhecendo a família como unidade de cuidado, a incapacidade funcional como balizadora de ações ${ }^{3}$ e o domicílio como o território onde as relações familiares, as condições socioculturais e sanitárias podem ser sensivelmente observadas ${ }^{10}$. Essa decisão passa pela efetiva implementação da $\mathrm{PNSPI}^{3}$, com definição de estratégias e de metas gerenciais para o Cuidado à família com idosos frágeis e de humanização e qualificação desse Cuidado.

\section{Considerações finais}

No presente trabalho, a compreensão da dinâmica das visitas domiciliárias das ACS às famílias com pessoas idosas frágeis expõe as fragilidades desta população, da família e da ESF para exercer o Cuidado, que fica comprometido porque o encontro não se faz com a pessoa idosa, mas com o "doente", o "decadente", o "incapaz", o "velho" cheio de "limitações e sofrimentos". Apesar de conseguirem perceber a importância da funcionalidade para a saúde do idoso, valorizam mais suas incapacidades, em uma perspectiva negativa, fatalista e "natural", reproduzindo, por meio da cultura, a visão da velhice difundida na sociedade ocidental.

No cotidiano do trabalho, enquanto se submetem a uma gestão vertical que cobra e é cobrada sobre a quantidade de visitas realizadas, as agentes modulam a criação e a intensidade do vínculo com os usuários idosos, para definir estratégias de atuação, aplicando critérios baseados na solidariedade a pessoas que conhecem e com as quais compartilham o mesmo contexto sociocultural. Para decidir sobre quem visitar, as agen- 
tes confrontam as demandas captadas no território, ao mesmo tempo em que observam que as necessidades em saúde da população assistida revelam necessidades de outra ordem (psíquica, emocional, econômica, social). Emergem daí dilemas entre o saber científico e o popular; entre o respeito a uma hierarquia técnica e vertical de poder, prisioneira de uma lógica funcionalista, produtivista e fragmentária e os valores relacionais de compaixão, solidariedade, reconhecimento e retribuição que elas anseiam.

Ainda que modulada por uma noção de "equidade solidária", sua atuação reforça um modelo assistencial médico-procedimento-centrado e uma assistência voltada ao indivíduo "doente". Algumas agentes relatam utilizar da escuta/diálogo como ferramenta de cuidado, seja por perceber que a pessoa idosa deseja ser escutada; por vislumbrar a importância dessa ferramenta no processo de cuidado, ainda que de forma intuitiva; ou por não ter outra "coisa" a fazer (medir pressão, glicemia) e ser esta a única ferramenta disponível. Assim, percebe-se a necessidade de investir em processos educativos para que os agentes se apoderem das ferramentas de Cuidado, especialmente, da escuta, qualificando-a, pois o ouvir por ouvir não favorece efetivamente o Cuidado.

Finalmente, o Cuidado também é comprometido pelo distanciamento que parece haver entre as ACS e a equipe. Assim, para alcançar os propósitos formais da ESF, é fundamental a equipe investir no diálogo com este ator, partilhando e aprendendo com ele sobre a cultura local, os anseios da comunidade e o cotidiano da atenção à saúde. É preciso ouvi-lo e também investir em capacitações e educação permanente sobre o cuidado a famílias com idosos que vivenciam perdas na sua funcionalidade, para que a visita domici- liária funcione como ferramenta diagnóstica, de planejamento e de reorientação do modelo assistencial à saúde. Caso contrário, as visitas servirão de instrumento para valorizar e assimilar a cultura de saúde como mero bem de consumo e não como direito a uma política pública universal e de qualidade para todo cidadão brasileiro, de todas as idades, inclusive aquele que, como o ACS, trabalha e utiliza o SUS.

\section{Colaboradores}

KA Magalhães trabalhou na concepção do projeto; coleta, análise e interpretação dos dados; e redação. KC Giacomin trabalhou na concepção do projeto; análise e interpretação dos dados; revisão crítica relevante do conteúdo intelectual e na aprovação da versão final. WJ Santos trabalhou na análise e interpretação dos dados e na redação. JOA Firmo trabalhou na concepção do projeto; coleta, análise e interpretação dos dados; revisão crítica relevante do conteúdo intelectual; e na aprovação da versão final.

\section{Agradecimentos}

Agradecemos à FAPEMIG pelo apoio financeiro, ao CNPq (bolsa de produtividade) e à CAPES (bolsa de doutorado). 


\section{Referências}

1. Uchôa E, Firmo JOA, Lima-Costa MF, Corin E. An anthropologic study on strategies for addressing heath problems among elderly in Bambuí, Minas Gerais, Brazil. Cad Saude Publica 2011; 27(Supl. 3):S370-377.

2. Fernandes MT, Soares SM. O Desenvolvimento de Políticas Públicas de atenção ao idoso no Brasil. Rev Esc Enferm USP 2012; 46(6):1494-1502.

3. Brasil. Ministério da Saúde. Portaria no 2.528, de 19 de outubro de 2006. Aprova a Política Nacional de Saúde da Pessoa Idosa. Diário Oficial da União 2006; 20 out.

4. Giacomin KC, Sartini CM, Matos SG. Modelo de atenção à saúde da pessoa idosa na rede SUS-BH. Rev Pensar BH/ Politica Social 2005; 13:3-9.

5. World Health Organization (WHO). International Classification of Functioning, Disability and Health. Geneva: WHO; 2001.

6. Alves LC, Leite IC, Machado CJ. Conceituando e mensurando a incapacidade funcional da população idosa: uma revisão de literatura. Cien Saude Colet 2008; 13(4):1199-1207.

7. Giacomin KC, Uchoa E, Lima-Costa MFF. Projeto Bambuí: a experiência do cuidado domiciliário por esposas de idosos dependentes. Cad Saude Publica 2005; 21(5):1509-1518

8. Sakata KN, Almeida MCP, Alvarenga AM, Craco PF, Pereira MJB. Concepções da equipe de saúde da família sobre as visitas domiciliares. Rev Bras Enferm 2007; 60(6):659-664.

9. Ferraz L, Aerts DRGC. O cotidiano de trabalho do agente comunitário de saúde no PSF em Porto Alegre. Cien Saude Colet 2005; 10(2):347-355.

10. Teixeira PC. Visita domiciliar: um instrumento de intervenção. Sociedade debate 2009; 15(1):165-178.

11. Loures LF, Silva MCS. A interface entre o trabalho do agente comunitário de saúde e do fisioterapeuta na atenção básica à saúde. Cien Saude Colet 2010; 15(4):2155-2164.

12. Brasil. Ministério da Saúde. Portaria GM/MS n 2.488 de 21 de outubro de 2011. Aprova a Política Nacional de Atenção Básica, estabelecendo a revisão de diretrizes e normas para a organização da Atenção Básica, para a Estratégia Saúde da Família (ESF) e o Programa de Agentes Comunitários de Saúde (PACS). Diário Oficial da União 2011; 24 out.

13. Ayres JRCM. Cuidado: trabalho e interação nas práticas de saúde. Rio de Janeiro: CEPESC- IMS/UERJ, Abrasco; 2011.

14. Pinheiro R. Integralidade do cuidado: a promessa da política e a confiança no direito. In: Pinheiro R, Martins $\mathrm{PH}$, organizadores. Usuários, redes sociais, mediações e integralidade em saúde. Rio de Janeiro: UERJ/ IMS/ LAPPIS; 2011. p. 51-66.

15. Minayo MCS, Souza ER, Constantino P, Santos NC. Métodos, técnicas e relações em triangulação. In: Minayo MCS, Assis SG, Souza ER, organizadores. Avaliação por Triangulação de Métodos: Abordagem de Programas Sociais. Rio de Janeiro: Editora Fiocruz; 2005. p. 71-103.

16. Minayo MCS, organizadora. Pesquisa Social: teoria, método e criatividade. 16a ed. Petrópolis: Ed. Vozes; 1994.

17. Turato ER. Métodos qualitativos e quantitativos na área da saúde: definições, diferenças e seus objetivos de pesquisa. Rev Saude Publica 2005; 39(3):507-514.
18. Uchôa E, Vidal JM. Antropologia Médica: Elementos Conceituais e Metodológicos para uma Abordagem da Saúde e da Doença. Cad Saude Publica 1994; 10(4):497504.

19. Geertz C. A interpretação das culturas. Rio de Janeiro: LTC - Livros Técnicos e Científicos Editora; 1989.

20. Adam P, Herzlich C. Sociologia da doença e da medicina. Bauru: Editora da Universidade do Sagrado Coração; 2000 .

21. Instituto Brasileiro de Geografia e Estatística (IBGE). Cidades@; Minas Gerais, Bambuí. [página da internet]. [acessado 2014 mar 11]. Disponível em: http:// www.cidades.ibge.gov.br/xtras/perfil.php?lang=\&codmun $=310510$ \&search $=$ minas - gerais $\mid$ bambui

22. Fontanella BJB, Luchesi BM, Saidel MGB, Ricas J, Turato ER, Melo DG. Amostragem em pesquisas qualitativas: proposta de procedimentos para constatar saturação teórica. Cad Saude Publica 2011; 27(2):389-394.

23. Corin E, Uchôa E, Bibeau G, Kouma-Re B. Articulation et variations des systèmes de signes, de sens et d'actions. Psychopathol Afr 1992; 24:183-204.

24. Firmo JOA, Lima-Costa MFF, Uchôa E. Projeto Bambuí: maneiras de pensar e agir de idosos hipertensos. Cad Saude Publica 2004; 20(4):1029-1040.

25. Uchôa E. Contribuições da Antropologia para uma Abordagem das Questões Relativas à Saúde do Idoso. Cad Saude Publica 2003; 19(3):849-853.

26. Uchôa E, Firmo JOA, Lima-Costa MFF. Envelhecimento e saúde: experiência e construção cultura. In: Minayo MCS, Coimbra Junior CEA, organizadores. Antropologia, saúde e envelhecimento. Rio de Janeiro: Fiocruz; 2002. p. 25-35.

27. Santos WJ, Giacomin KC, Pereira JK, Firmo JOA. Enfrentamento da incapacidade funcional por idosos por meio de crenças religiosas. Cien Saude Colet 2013; 18(8):2319-2328.

28. Moraes GVO. Influência do Saber Biomédico na Percepção da Relação Saúde/Doença/Incapacidade em Idosos da Comunidade [dissertação]. Belo Horizonte: Centro de Pesquisas René Rachou, Fundação Oswaldo Cruz; 2012.

29. Pereira JK, Firmo JOA, Giacomin KC. Maneiras de pensar e de agir de idosos frente às questões relativas à funcionalidade/incapacidade. Cien Saude Colet 2014; 19(8):3375-3384.

30. Takahashi RF, Oliveira MAC. A visita domiciliária no contexto da saúde da família. In: Brasil. Instituto para o Desenvolvimento da Saúde. Universidade de São Paulo. Ministério da Saúde (MS), organizador. Manual de enfermagem. Brasília: MS; 2001. p. 43-46.

31. Pinheiro R, Martins PH, organizadores. Usuários, Redes sociais, mediações e integralidade em saúde. Rio de Janeiro: UERJ/IMS/LAPPIS; 2011.

32. Franco TB, Andrade CS, Coelho VSF, organizadores. A Produção Subjetiva do Cuidado: cartografias da estratégia saúde da família. São Paulo: Editora Hucitec; 2009.

33. Cunha MS, Sá MC. A visita domiciliar na Estratégia de Saúde da Família: os desafios de se mover no território. Interface (Botucatu) 2013; 17(44):61-73.

34. Galavote HS, Prado TN, Maciel ELN, Lima RCD. Desvendando os processos de trabalho do agente comunitário de saúde nos cenários revelados na Estratégia Saúde da Família no município de Vitória (ES, Brasil). Cien Saude Colet 2011; 16(1):231-240. 
35. Lima NA, Silva L, Bousso RS. A visita domiciliária realizada pelos agentes comunitários de saúde sob a ótica de adultos e idosos. Saude Soc 2010; 19(4):889-897.

36. Aristóteles. Ética a Nicômaco. Brasília: Ed. Universidade de Brasília; 1985.

37. Camarano AA. Cuidados de longa duração para a população idosa: um novo risco social a ser assumido? In: Camarano AA. Cuidados de longa duração para a população idosa: um risco social a ser assumido? Rio de Janeiro: IPEA; 2010. p. 337-349.

38. Brasil. Ministério da Saúde. Caderneta de Saúde da Pessoa Idosa. [acessado 2014 maio 4]. Disponível em: http://bvsms.saude.gov.br/bvs/publicacoes/caderneta_saude_pessoa_idosa.pdf

39. França SP, Pessoto UC, Gomes JO. Capacitação no Programa de Saúde da Família: divergências sobre o conceito de visita domiciliar nas equipes de Presidente Epitácio, São Paulo. Trab. educ. saúde 2006; 4(1):93-108.

40. Nakata PT, Koltermann LI, Vargas KR, Moreira PW, Duarte ERM, Rosset-Cruz I. Classification of Family Risk in a Family Health Center. Rev Lat Am Enfermagem 2013; 21(5):1088-1095.

41. Merhy EE. Saúde: a cartografia do Trabalho Vivo. São Paulo: Hucitec; 2002.

42. Nogueira RP, Silva F, Ramos Z. A vinculação institucional de um trabalhador sui generis o agente comunitário de saúde. [Textos para discussão $n^{\circ} 735$ ] 2000. [acessado 2013 jun 15]. Disponível em: http:www.ipea.gov.br/ pub/td/td_2000/td0735.pdf

43. Silva JA, Dalmaso ASW. Agente Comunitário de Saúde: o ser, o saber, o fazer. Rio de Janeiro: Editora Fiocruz; 2002.

44. Santos KT, Saliba NA, Moimaz SAS, Arcieri RM, Carvalho ML. Agente comunitário de saúde: perfil adequado à realidade do Programa Saúde da Família? Cien Saude Colet 2011; 16(Supl. 1):1023-1028.

Artigo apresentado em 13/06/2014

Aprovado em 13/12/2014

Versão final apresentada em 15/12/2014 